\title{
Effect of UV radiation and temperature on the emission of methane from plant biomass and structural components
}

\author{
I. Vigano ${ }^{1}$, H. van Weelden ${ }^{2}$, R. Holzinger ${ }^{1}$, F. Keppler ${ }^{3}$, A. McLeod ${ }^{4}$, and T. Röckmann ${ }^{1}$ \\ ${ }^{1}$ Institute for Marine and Atmospheric research Utrecht (IMAU), Utrecht University, Princetonplein 5, \\ 3584ED Utrecht, The Netherlands \\ ${ }^{2}$ Department of Dermatology and Allergology Utrecht University Medical Center Utrecht, Heidelberglaan 100, 3584CX \\ Utrecht, The Netherlands \\ ${ }^{3}$ Max-Planck-Institute for Chemistry, Joh.-Joachim-Becher-Weg 2, 55128 Mainz, Germany \\ ${ }^{4}$ School of GeoSciences, University of Edinburgh, Crew Building, The King's Buildings, West, UK
}

Received: 7 December 2007 - Published in Biogeosciences Discuss.: 21 January 2008

Revised: 8 May 2008 - Accepted: 1 June 2008 - Published: 26 June 2008

\begin{abstract}
The recently reported finding that plant matter and living plants produce significant amounts of the important greenhouse gas methane under aerobic conditions has led to an intense scientific and public controversy. Whereas some studies question the up-scaling method that was used to estimate the global source strength, others have suggested that experimental artifacts could have caused the reported signals, and two studies, one based on isotope labeling, have recently reported the absence of $\mathrm{CH}_{4}$ emissions from plants. Here we show - using several independent experimental analysis techniques - that dry and detached fresh plant matter, as well as several structural plant components, emit significant amounts of methane upon irradiation with UV light and/or heating. Emissions from UV irradiation are almost instantaneous, indicating a direct photochemical process. Longtime irradiation experiments demonstrate that the size of the $\mathrm{CH}_{4}$ producing reservoir is large, exceeding potential interferences from degassing or desorption processes by several orders of magnitude. A dry leaf of a pure ${ }^{13} \mathrm{C}$ plant produces ${ }^{13} \mathrm{CH}_{4}$ at a similar rate as dry leaves of non-labeled plants produce non-labeled methane.
\end{abstract}

\section{Introduction}

Methane $\left(\mathrm{CH}_{4}\right)$ is the second most important anthropogenic greenhouse gas after $\mathrm{CO}_{2}$ (Forster et al., 2007) and the most abundant reduced organic compound in the atmosphere, which makes it an important participant in atmospheric chemistry. According to established knowledge, it is produced primarily by anaerobic bacterial activity in wet-

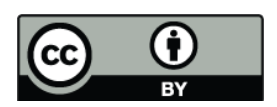

Correspondence to: T. Röckmann

(t.roeckmann@uu.nl) lands, rice fields, landfills and the gastrointestinal tract of ruminants, with non-bacterial emissions occurring from fossil fuel usage and biomass burning. The main tropospheric sink of $\mathrm{CH}_{4}$ is chemical removal by the hydroxyl $(\mathrm{OH})$ radical. Microbial uptake in soils and loss to the stratosphere are small sinks. Recently, Keppler et al. (2006) published results from laboratory experiments indicating that living plants, plant litter and the structural plant component pectin emit methane to the atmosphere under aerobic conditions. These findings are heavily debated, since they have far-reaching implications, mainly for two reasons: (1) It is generally believed that the reduced compound $\mathrm{CH}_{4}$ can only be produced naturally from organic matter in the absence of oxygen, or at high temperatures, e.g. in biomass burning, and in fact no mechanism for an "aerobic" production process has been identified at the molecular level. (2) The first extrapolations from the laboratory measurements to the global scale indicated that these emissions could constitute a large fraction of the total global emissions of $\mathrm{CH}_{4}$.

After publication of the paper, in particular the second point and the underlying extrapolation procedure were criticized, and other up-scaling calculations were performed, which would result in a lower - but potentially still important - source strength (Butenhoff and Khalil, 2007; Ferretti et al., 2006; Houweling et al., 2006; Kirschbaum et al., 2006, 2007; Bergamaschi et al., 2006). It should be kept in mind, however, that without further insight into the nature of the production process, any up-scaling approach bears considerable uncertainties. For example, it is not known yet which parts of plants (e.g. leaves, roots, stems) emit how much $\mathrm{CH}_{4}$ and how this depends on environmental parameters. This uncertainty was acknowledged by Keppler et al. (2006), who presented their result as a first estimate. On the other hand, if an aerobic $\mathrm{CH}_{4}$ production mechanism exists, then there

Published by Copernicus Publications on behalf of the European Geosciences Union. 
are independent indications that it could be indeed a large source. For example, satellite and recent aircraft observations suggest a strong $\mathrm{CH}_{4}$ source in the tropical forest region (Frankenberg et al., 2005; Frankenberg et al., 2006; Miller et al., 2007) and attempts to combine the satellite observations with the existing ground network require significantly higher $\mathrm{CH}_{4}$ emissions in the tropics (Bergamaschi et al., 2007). In addition, the high ${ }^{13} \mathrm{C}$ content of methane before 1500 a.d. as recovered from ice cores (Ferretti et al., 2005 ) is hard to reconcile with the standard picture that preindustrial emissions were dominated by isotopically depleted wetland emissions. The initial hypothesis that pre-industrial anthropogenic biomass burning caused the high ${ }^{13} \mathrm{C}$ levels (Ferretti et al., 2005) is questioned by new data that show an even higher ${ }^{13} \mathrm{C}$ content in the early Holocene (Schaefer et al., 2006). Thus the high biomass burning levels would have to be natural, but an alternative scenario that involves significant levels of vegetation emissions has also been suggested (Houweling et al., 2006, 2007). Direct atmospheric measurements (Crutzen et al., 2006; do Carmo et al., 2006; Sanhueza and Donoso, 2006; Sinha et al., 2007) are consistent with $\mathrm{CH}_{4}$ emissions from plants. The most recent published study reported $\mathrm{CH}_{4}$ emissions from shrubs in the inner Mongolian steppe, but not from grasses (Wang et al., 2007). However, here remains considerable doubt about the existence of $\mathrm{CH}_{4}$ emissions from vegetation.

Therefore, the principle scientific questions are: if, by how much and by what mechanisms is methane emitted from plant matter under normal atmospheric conditions and without bacterial activity? The first follow-up study (Dueck et al., 2007) did not confirm the findings: No ${ }^{13} \mathrm{CH}_{4}$ emissions were found from plants, which were grown in a ${ }^{13} \mathrm{CO}_{2}$ atmosphere and should thus have produced ${ }^{13} \mathrm{CH}_{4}$ only. Beerling et al. (2008) similarly reported no $\mathrm{CH}_{4}$ emissions from a $\mathrm{C} 3$ and a $\mathrm{C} 4$ species but suggested a possible role of nonenzymatic processes with an action spectrum outside the photosynthetically-active range. Nevertheless, to the best of our knowledge there is no scenario other than direct emissions from the plant matter that can explain the (natural abundance) isotope signatures observed in the earlier experiments by Keppler et al. (2006).

Facing this important apparent contradiction we designed a series of measurements in order to investigate whether an aerobic $\mathrm{CH}_{4}$ production mechanism indeed exists. In order to exclude potentially complicating factors from living plants we restricted this project to dry and fresh plant matter, as well as defined structural plant components such as pectin, lignin and cellulose. Therefore, effects related to photosynthesis and respiration do not interfere, for example, it is not necessary to actively stabilize $\mathrm{CO}_{2}$ concentrations and we eliminate potential problems due to high levels of water vapour from transpiration of living plants. We also avoided possible artifacts that can be associated with static enclosure systems by using dynamic flow reactors.

\section{Experimental}

The study of Keppler et al. (2006) had indicated that the $\mathrm{CH}_{4}$ emissions from plants and plant matter are light and temperature dependent. Therefore, we irradiated more than 20 types of dry and fresh plant matter (see Table 1), as well as several structural plant compounds, with different light sources covering the wavelength range from visible light to UVC. The experiments were mostly carried out in dynamic UV transparent (Suprasil) flow reactors rather than the static chambers used previously. The substrates were placed in $\sim 50, \sim 100$ or $\sim 300 \mathrm{ml}$ volume glass or Suprasil vials, which were purged with 100 to $500 \mathrm{ml} / \mathrm{min}$ of either dry air (normal ambient $\mathrm{CH}_{4}$ concentration) or dry synthetic air (no methane). The $\mathrm{CH}_{4}$ production rate was determined from the difference in concentrations of the in- and out-flowing air and the air flow rate. In some experiments we also used humidified air, and in those cases the water content of the reference and sample air was set to a common level using a humidity exchanger (Nafion), in order to avoid artificial mixing ratio changes arising from different humidity. Additional heating experiments were carried out by heating the Suprasil vials with heating tape to temperatures up to $100^{\circ} \mathrm{C}$.

Three different methods were used to quantify $\mathrm{CH}_{4}$ levels:

1. An off-axis integrated cavity output spectrometer (Los Gatos Inc.) that allows real-time high-precision monitoring of $\mathrm{CH}_{4}$ mixing ratios at a frequency up to $10 \mathrm{~Hz}$ and with a precision of $\pm 2 \mathrm{ppb}$ for 5 -s averaged data. No cross-sensitivities from other species are known for this instrument, and we verified this for the abundant plant emission $\mathrm{CH}_{3} \mathrm{OH}$

2. A GC-FID instrument for grab sample analysis (reproducibility $\pm 10 \mathrm{ppb}$ ) for occasional cross-check for the optical technique and for the experiments with small static vials, where the small sample amount does not allow measurements with the optical system.

3. The isotope ratio mass spectrometry (IRMS) technique, also used by Keppler et al. (2006), to measure not only the concentration (reproducibility $\pm 20 \mathrm{ppb}$ at ambient concentration), but also the ${ }^{13} \mathrm{C}$ and $\mathrm{D}$ isotopic composition of the $\mathrm{CH}_{4}$.

As light sources we used 6 types of lamps: A Philips 400W HPS Na lamp, four UVA and UVB lamps (20W Phillips TL01, TL09, TL12, TUV (15W) and Osram Vitalux (300W), spectra are shown in the Appendix), and one 5W Radium NTE-220 HG penray UVC lamp (Oriel Instruments) with the typical emission line at $254 \mathrm{~nm}$. The UVC penray lamp was placed inside a Suprasil finger protruding inside the sample vial and was thus at $1-2 \mathrm{~cm}$ distance from the sample. This may lead to heating of the material, which was not measured. All other lamps irradiated the sample from the top. In case of the Osram Vitalux lamp, a single lamp was used, whereas 
Table 1. List of selected $\mathrm{CH}_{4}$ production experiments carried out with UV radiation.

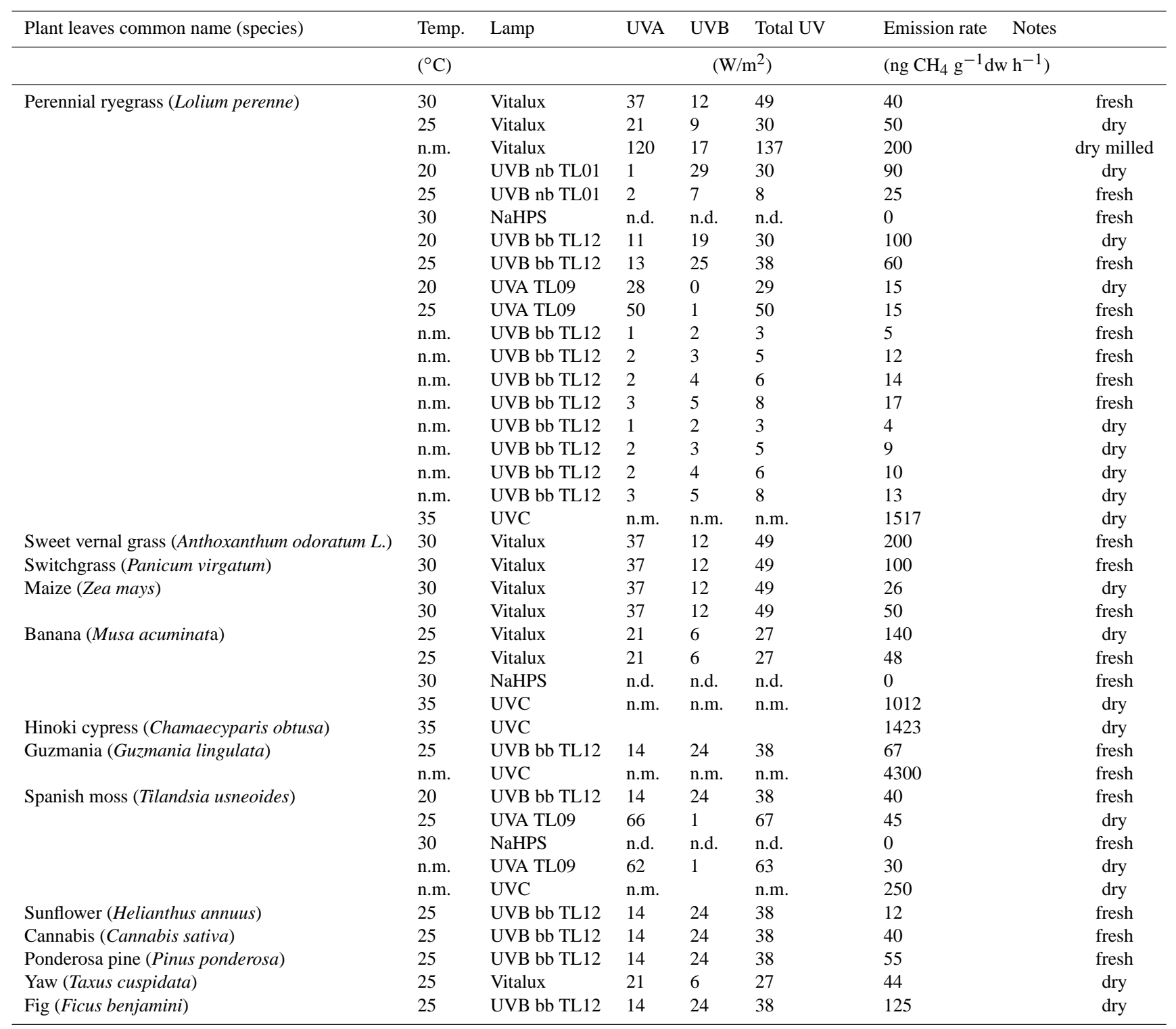

n.m.: not measured

n.d.: not determined

for the three Phillips lamp types we used an array of six UV lamps. The UV content (UVA and UVB separately) was determined with a Waldmann UV meter (Waldmann, Schwenningen, Germany) calibrated for each individual UV lamp, except for the UVC lamp. The relative spectral distribution measurements and the calibration of the Waldmann device were performed with a calibrated standard UV-visible spectroradiometer (model 752, Optronic Laboratories Inc, USA).

In the absence of a reliable action spectrum for $\mathrm{CH}_{4}$ release from biomass upon UV irradiation, the UV strength is reported as the non-weighted integral over the UVA range (400-320 nm), UVB range (320-280 nm) or total UV range (400-280 nm). Except for the $\mathrm{Hg}$ lamp, and a very small amount from the TL12 lamps, the lamps do not emit in the UVC range. In most experiments unfiltered light was used, but tests were carried out with a cellulose diacetate filter in order to investigate the influence from short-wave radiation (see below).

Choosing this approach (using unfiltered, non-weighted UV radiation) we neglect a possible wavelength dependence of the biologically effective dose. This has to be kept in mind when comparing the observed emissions to the real atmosphere. For example, when we irradiate the material with an integrated UVB amount similar to the atmosphere, the individual lamps still possess strongly (TL01) or slightly (TL12, VITALUX) more shortwave UVB radiation (loosely 
Table 1. Continued.

\begin{tabular}{|c|c|c|c|c|c|c|c|}
\hline Plant leaves common name (species) & Temp. & Lamp & UVA & UVB & Total UV & Emission rate & Notes \\
\hline & \multicolumn{2}{|l|}{$\left({ }^{\circ} \mathrm{C}\right)$} & & \multicolumn{2}{|c|}{$\left(\mathrm{W} / \mathrm{m}^{2}\right)$} & \multicolumn{2}{|c|}{$\left(\mathrm{ng} \mathrm{CH} \mathrm{CH}_{4} \mathrm{~g}^{-1} \mathrm{dw} \mathrm{h}^{-1}\right)$} \\
\hline & 25 & UVB bb TL12 & 14 & 24 & 38 & 80 & fresh \\
\hline & 40 & UVB bb TL12 & 14 & 24 & 38 & 120 & fresh \\
\hline & n.m. & UVC & n.m. & n.m. & n.m. & 998 & dry \\
\hline & 30 & NaHPS & n.d. & n.d. & n.d. & 0 & fresh \\
\hline Nettle (Urtica dioica) & 25 & UVB bb TL12 & 14 & 24 & 38 & 67 & fresh \\
\hline \multirow[t]{2}{*}{ Bamboo (Phyllostachys aurea) } & 30 & UVB bb TL12 & 14 & 24 & 38 & 56 & dry \\
\hline & 30 & UVB bb TL12 & 14 & 24 & 38 & 134 & fresh \\
\hline Rhododendron (Rhododendron maximum) & 25 & Vitalux & 21 & 6 & 27 & 16 & dry \\
\hline \multicolumn{8}{|l|}{ Different Plant material } \\
\hline \multirow{2}{*}{ Cotton (Gossypium hirsutum) } & 25 & UVB bb TL12 & 14 & 24 & 38 & 22 & flower \\
\hline & 25 & Vitalux & 21 & 6 & 27 & 393 & flower \\
\hline \multirow[t]{2}{*}{ Ponderosa Pine (Pinus ponderosa) } & 25 & UVB bb TL12 & 14 & 24 & 38 & 10 & bark \\
\hline & 25 & Vitalux & 21 & 6 & 27 & 50 & bark \\
\hline Sequoia (Sequoia sempervirens) & 25 & UVB bb TL12 & 14 & 24 & 38 & 7 & bark \\
\hline Robinia (Robinia pseudoacacia) & 25 & UVB bb TL12 & 14 & 24 & 38 & 9 & bark \\
\hline \multirow[t]{2}{*}{ moss (Hylocomium splendens) } & 30 & UVB bb TL12 & 14 & 24 & 38 & 75 & dry leaves \\
\hline & 40 & UVB bb TL12 & 14 & 24 & 38 & 150 & dry leaves \\
\hline \multicolumn{8}{|l|}{ Structural Plant Compounds } \\
\hline \multirow[t]{2}{*}{ Cellulose } & n.m. & Vitalux & 120 & 17 & 137 & 8 & dry \\
\hline & 35 & UVB bb TL12 & 14 & 24 & 38 & 32 & dry \\
\hline Citrus Pectin $90 \%$ esterified & 30 & UVB bb TL12 & 14 & 24 & 38 & 60 & dry \\
\hline \multirow[t]{8}{*}{ Apple Pectin } & 25 & UVB bb TL12 & 14 & 24 & 38 & 20 & dry \\
\hline & n.m. & UVB bb TL12 & 1 & 2 & 3 & 4 & dry \\
\hline & n.m. & UVB bb TL12 & 2 & 3 & 5 & 5 & dry \\
\hline & n.m. & UVB bb TL12 & 2 & 4 & 6 & 6 & dry \\
\hline & n.m. & UVB bb TL12 & 3 & 5 & 8 & 9 & dry \\
\hline & n.m. & UVC & n.m. & n.m. & n.m. & 190 & dry \\
\hline & n.m. & Vitalux & 120 & 17 & 137 & 85 & dry \\
\hline & 30 & NaHPS & n.d. & n.d. & n.d. & 0 & dry \\
\hline \multirow[t]{6}{*}{ Lignin } & 25 & UVB bb TL12 & 14 & 24 & 38 & 16 & dry \\
\hline & n.m. & UVB bb TL12 & 1 & 2 & 3 & 0.5 & dry \\
\hline & n.m. & UVB bb TL12 & 2 & 3 & 5 & 0.7 & dry \\
\hline & n.m. & UVB bb TL12 & 2 & 4 & 6 & 2 & dry \\
\hline & n.m. & UVB bb TL12 & 3 & 5 & 8 & 3 & dry \\
\hline & n.m. & Vitalux & 120 & 17 & 137 & 32 & dry \\
\hline \multirow[t]{3}{*}{ Palmitic acid } & 30 & UVB bb TL12 & 14 & 24 & 38 & 0 & dry \\
\hline & 30 & Vitalux & 39 & 12 & 51 & 0 & dry \\
\hline & n.m. & UVC & n.m. & n.m. & n.m. & 15 & dry \\
\hline
\end{tabular}

defined as wavelengths below $295 \mathrm{~nm}$ ) than the natural solar spectrum at the surface of the earth, where such wavelengths are virtually absent. The possible effects of higher levels of shortwave radiation will be discussed below, as well as first semi-quantitative information on an action spectrum.

To increase signal to noise ratio, the average non-weighted UVB intensity used in the experiments was 5 times higher than natural UVB levels, in some experiments even $>10$ times higher, but we also carried out experiments at close to natural total UV levels. Temperatures were mostly determined directly at the leaf surface with a micro-thermocouple attached to the material, in the early experiments the gas temperature was measured.

Blank experiments were carried out by repeating the same experiment under identical conditions but without the organic matter sample. In none of the blank experiments could we detect any $\mathrm{CH}_{4}$ production. 


\section{Materials}

The full list of materials investigated in the irradiation experiments is given in Table 1. Most of the plant material was obtained from the botanical garden of Utrecht University, some leaves were collected from regular outside plants or plants grown inside a building. Material was dried by heating the plants in an oven overnight at $80-100^{\circ} \mathrm{C}$. Fresh materials were usually analyzed within 1 hour after detachment from the living plant. The organic compounds used for experiments were obtained from Sigma (apple pectin, purity 95\%, CAS number 9000-69-5, cellulose microcrystalline, purity 95\%, CAS number 9004-34-6, pectin esterified from citrus fruit, purity $99 \%$, CAS number 37251-70-0, lignin, purity 95\%, CAS number 8068-05-1, palmitic acid, Grade II, purity $95 \%$, CAS number 57-10-3). In a typical experiment we used between 0.1 and $5 \mathrm{~g}$ of dry material.

\section{Results and discussion}

4.1 Methane emission from organic matter - the effect of UV light and temperature

Significant amounts of methane were produced from all materials when irradiated with lamps that contain UV radiation (Table 1), but the emissions were below the detection limit of the dynamic flow system $(\sim 2 \mathrm{ng} / \mathrm{g} \mathrm{dw} / \mathrm{h}$, improved in the later experiments) when a $\mathrm{Na}$ lamp with a cutoff wavelength of $\sim 400 \mathrm{~nm}$, i.e., without UV radiation, was used. To investigate the dependence of the $\mathrm{CH}_{4}$ emission on wavelength in the UV range, we adjusted the distance to the different lamps such that in 4 similar experiments with the same sample of dry grass (Lolium perenne) the sample received the same total UV content $(280-400 \mathrm{~nm}$, without filters and unweighted) of $30 \mathrm{~W} / \mathrm{m}^{2}$ from all four UV lamps. To avoid excessive heating, in those experiments the vial was cooled from the outside with a strong ventilator and the temperature did not exceed $28^{\circ} \mathrm{C}$, which is only slightly above the lab temperature of $22^{\circ} \mathrm{C}$.

The results imply that UVB radiation is more efficient than UVA radiation in inducing $\mathrm{CH}_{4}$ emission, giving first qualitative information about the UV action spectrum (Fig. 1): the highest emissions are obtained with the broad band and narrow band UVB lamps (Phillips TL01 and TL12), followed by the Osram Vitalux lamp, which has the largest part of its UV content in the UVA region, and the lowest emission are obtained with the UVA lamp (Phillips TL09). Emissions with the UVC penray lamp are still significantly higher than with the UVB lamp, but cannot be directly compared to the other lamps since the irradiation geometry is different.

To further investigate the wavelength dependence of the emission rates, two optical filters were used: a) a cellulose diacetate filter that strong attenuates short-wave UVB radiation (transmission $<1 \%$ below $291 \mathrm{~nm}$ ) and b) a sheet of window

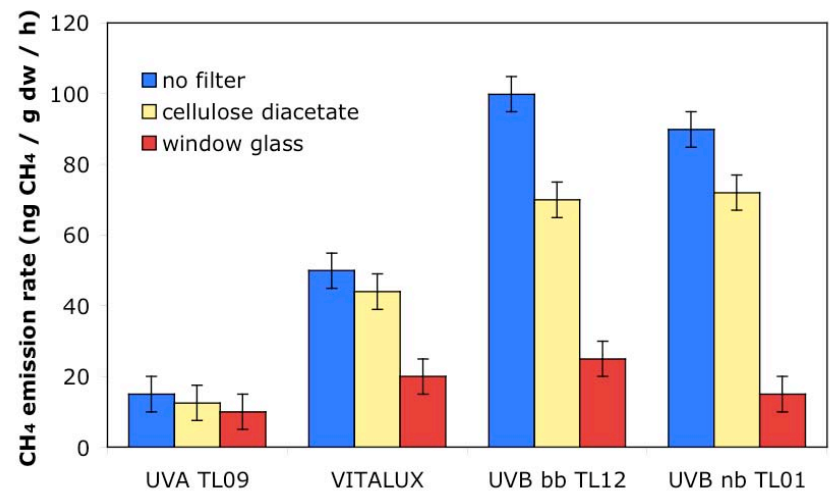

Fig. 1. Emission rate from a grass sample (Lolium perenne) irradiated with different lamps with the same total UV content (blue bars). The ER increases with increasing relative UVB content. The emission rate decreases when a cellulose diacetate filter (yellow bars) or a glass sheet (red bars) are placed between the vial and the lamp. Error bars are derived from the noise level of the optical instrument.

glass that blocks virtually all UVB radiation (transmission $<1 \%$ below $323 \mathrm{~nm}$ ). Those filters reduce the total amount of UV radiation reaching the sample and also the $\mathrm{CH}_{4}$ emission rates, as shown in Fig. 1. The cellulose diacetate filter reduces the total UV radiation (unweighted) from the broadband UVB lamp (TL12) by $\sim 20 \%$, and the $\mathrm{CH}_{4}$ emission by $\sim 30 \%$. This indicates a slightly, but not extremely increased efficiency in $\mathrm{CH}_{4}$ production of those wavelengths that are preferentially filtered $(\lambda<290 \mathrm{~nm})$. For the other lamps, the changes in emission rate and the reduction of the total UV radiation are not significantly different. A similar conclusion can be drawn from the results of the unfiltered TL01 and TL12 lamps. At the same level of total UV radiation, the emission rates are very similar, although the spectral distribution is strongly different (see Appendix). The fraction of UVB radiation shorter than $295 \mathrm{~nm}$ is $13 \%$ for the TL12 lamp, but only $0.5 \%$ for the TL01. The absence of a strong difference in emission rates and the results with the cellulose diacetate filter indicate that the action spectrum for $\mathrm{CH}_{4}$ production may not be very steep in the UVB region, in contrast to, e.g., the action spectrum for human erythema or DNA damage.

The window glass reduces the emission rates much more strongly. The reductions are strongest for the UVB rich light sources and are not significant for the UVA lamp, which again highlights the important role of UVB radiation (Fig. 1).

Several of the lamps used for photolysis are based on a $\mathrm{Hg}$ arc, and thus also emit small traces of UVC radiation at $254 \mathrm{~nm}$. The figure in the Appendix indicates that those traces are highest for the TL01 and TL12 lamps. To investigate a possible disproportionate effect from this very small fraction of UVC radiation, a similar lamp that irradiates only the $\mathrm{Hg}$ arc (UVC) was used. At a similar total UV level, the UVC lamp produces nine times higher $\mathrm{CH}_{4}$ emissions than 


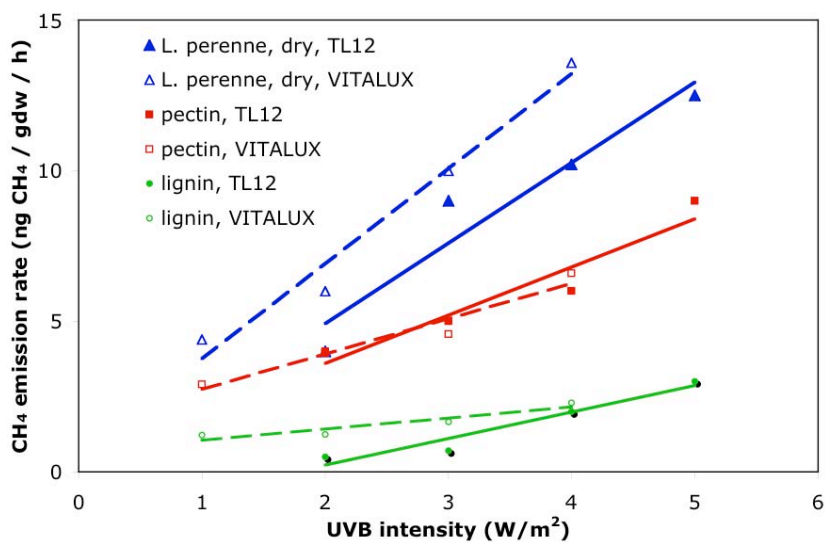

Fig. 2. Dependence of the $\mathrm{CH}_{4}$ emission rate from dry grass $(L$. perenne, blue), pectin (red) and lignin (Zimmerman et al.) on UVB intensity over the naturally occurring UVB range (unweighted) using the TL12 (solid symbols and linear trend lines) and the VITALUX (open symbols and dashed linear trend lines) lamps.

the TL01 lamp. This again implies a wavelength dependence, but excludes a disproportionate effect from the UVC wavelengths. These experiments provide important first semiquantitative information about the action spectrum, as called for in (Kirschbaum et al., 2006), but a full deconvolution is beyond the scope of this work.

Typical ambient (non-weighted) summer UVB irradiances near the Earth surface range from $2 \mathrm{~W} / \mathrm{m}^{2}$ at mid latitudes to $4 \mathrm{~W} / \mathrm{m}^{2}$ in the tropics (Bernhard et al., 1997). When biomass is irradiated with similar non-weighted levels of total UVB, $\mathrm{CH}_{4}$ emissions increase linearly with UVB intensity (Fig. 2). Typical emission rates in the temperature range from 25 to $40^{\circ} \mathrm{C}$ are 7 to $50 \mathrm{ng} \mathrm{CH}_{4} / \mathrm{g} \mathrm{dw} / \mathrm{h}$ ( $\mathrm{g} \mathrm{dw}=$ gram dry weight). It should be kept in mind that a full action spectrum is required to compare those emission rates to the atmospheric situation, however, our experiments with different light sources and filters indicate that the slope of the action spectrum may be rather low. This implies that the $\mathrm{CH}_{4}$ emissions reported here may not be strongly affected by details in the spectral distribution. The $\mathrm{CH}_{4}$ emission rates under UV irradiation are significantly higher than reported by Keppler et al. (2006) for their experiments with plant litter, which were carried out without UV irradiation, but lower than their emissions from living plants, even without light. Emissions of methane increase linearly with the amount of material irradiated, so that it is adequate to report the emission rates per amount of material (units ng $\mathrm{CH}_{4} / \mathrm{g} \mathrm{dw} / \mathrm{h}$ ). The linear dependence of $\mathrm{CH}_{4}$ emission rate on light intensity provides the link to the results in the following part of the paper, where we used UV intensities up to 10 times higher than typical tropical surface values in order to increase signal to noise level of the analytical system. As mentioned above, blank experiments without an organic matter sample showed no detectable $\mathrm{CH}_{4}$ production.
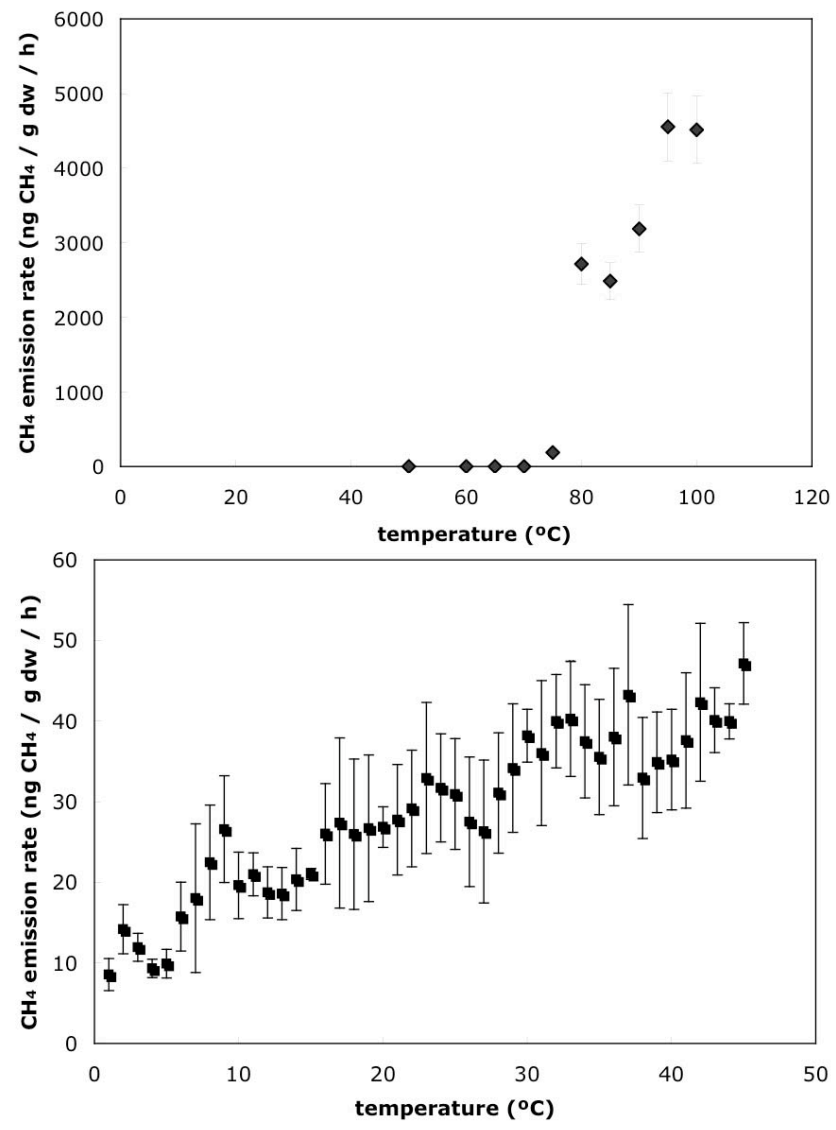

Fig. 3. Dependence of the emission rate from dry milled grass (Lolium perenne) on temperature without UV irradiation (a) and with UV light ( $5 \mathrm{~W} / \mathrm{m}^{2} \mathrm{UVB}$ ) from the Philips UVB bb TL12 lamp (b). Error bars in (a) are derived from the uncertainty of the concentration measurements, error bars in (b) denote the average of three similar experiments.

In addition to UV light, heating also leads to $\mathrm{CH}_{4}$ emissions, as was already shown by Keppler et al. (2006). However, irradiation with UV strongly changes the temperature dependence (Fig. 3). Without UV irradiation, $\mathrm{CH}_{4}$ production is not detectable in our dynamic system (below $2 \mathrm{ng} / \mathrm{g} \mathrm{dw} / \mathrm{h}$ ) until the temperature reaches $70-80^{\circ} \mathrm{C}$, at which the emission rate increases sharply. Under UV irradiation with the broadband UVB lamp TL12 $\left(5 \mathrm{~W} / \mathrm{m}^{2} \mathrm{UVB}\right.$, i.e., similar to typical tropical noon levels, but unweighted), emissions are already significant at room temperature and increase almost linearly with increasing temperature in the ambient temperature range from 0 to $50^{\circ} \mathrm{C}$. This difference in emission behaviour indicates at least two different production mechanisms. The low-temperature UV facilitated emissions are expected to be ubiquitous. Both the linear increase of methane emissions observed during irradiation with UV light as well as the strong emission of methane at elevated temperatures rule out a microbial mediated formation pathway. 


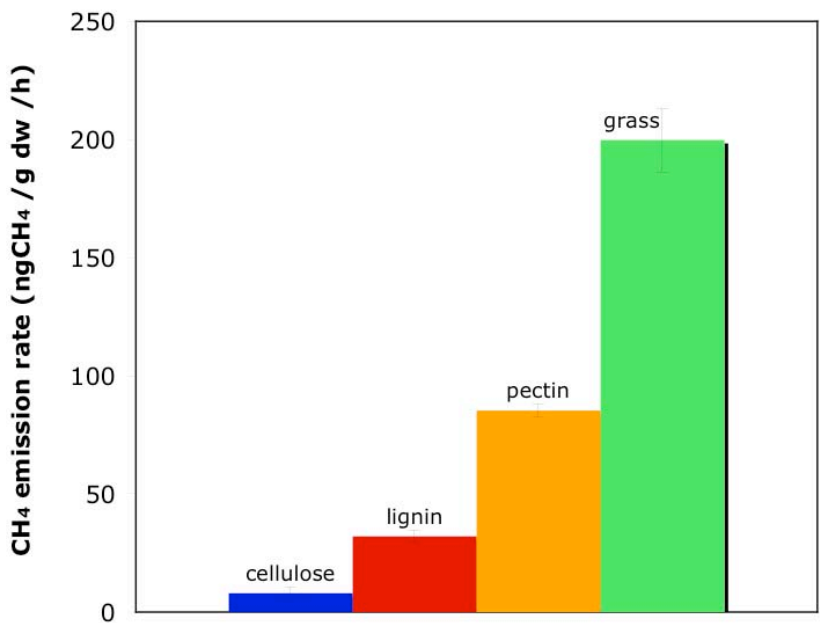

Fig. 4. Comparison of methane emission rates from dry grass and various plant structural compounds under UV irradiation (Vitalux lamp, UVA $53 \mathrm{~W} / \mathrm{m}^{2}$, UVB $7.4 \mathrm{~W} / \mathrm{m}^{2}$ ). Error bars are derived from the uncertainty in the concentration measurement.

Similar experiments were carried out with the structural plant components pectin, lignin, cellulose and palmitic acid. In addition to pectin, which was already studied by Keppler et al. (2006), also lignin and cellulose emit significant amounts of $\mathrm{CH}_{4}$ upon irradiation with UV light (Fig. 4). On the other hand emissions of $\mathrm{CH}_{4}$ from palmitic acid, a component in the cutin layer of plants, are very low, but can be "forced" by using a higher dose of UV light.

In particular the emissions from cellulose, the primary structural component of green plants, are noteworthy. Keppler et al. (2006) suggested that esterified methyl groups could be the source substrate for $\mathrm{CH}_{4}$ production in pectin. In fact new results by Keppler et al. (2007) show isotopic evidence that methyl esterified groups of pectin can act as a precursor for methane formation under aerobic conditions. Cellulose does not possess such groups, and thus our results imply (if those emissions are not caused by contamination from impurities) that $\mathrm{UV}$ irradiation leads to $\mathrm{CH}_{4}$ production from other carbon moieties of polysaccharides, in addition to the methoxyl groups. Interestingly, a free radical process has recently been suggested for the formation of methane from polysaccharides under the influence of UV light (Sharpatyi, 2007) Fig. 4 shows that under comparable conditions emission rates of dry plant material are generally higher than from the individual chemical components, with emissions from cellulose being significantly lower than those from pectin and lignin. Similarly, emissions from cotton flower (Gossypium hirsutum), which consists primarily of pure cellulose, are much stronger than from the synthetic compound (Table 1).

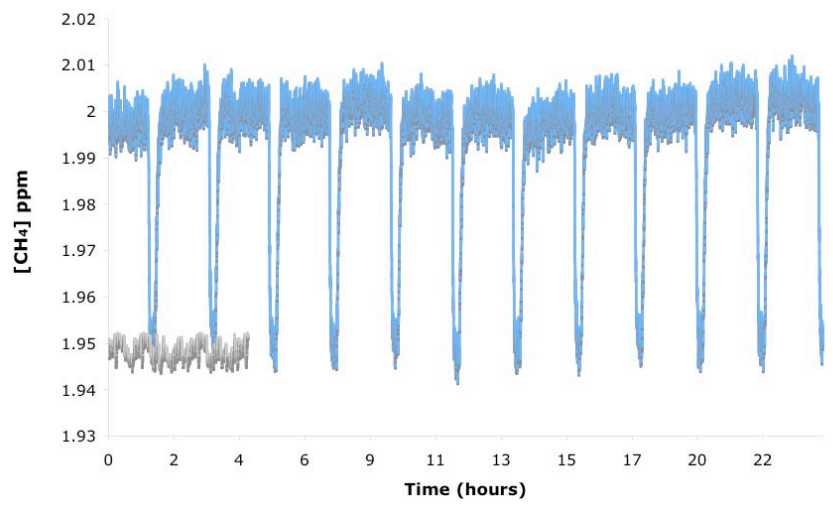

Fig. 5. Typical $24 \mathrm{~h}$ snapshot of raw $\mathrm{CH}_{4}$ concentration data (blue line) from the optical instrument during the long time UV irradiation experiment. During each $2 \mathrm{~h}$ period the UV lamp is switched on for $105 \mathrm{~min}$ and off for 15 minutes to monitor possible instrument drift and to continuously verify that the $\mathrm{CH}_{4}$ emission signal is related to UV irradiation. Numerous blank tests without samples were performed and the grey line shows a $\sim 4 \mathrm{~h}$ blank test using the same bottle of compressed air. UV light was switched on and off respectively for $1 \mathrm{~h}$ periods and no $\mathrm{CH}_{4}$ emission is observed without an organic matter sample.

\subsection{Characterization of the substrate reservoir and the emission process}

The experiments described so far were carried out for periods of hours to several days. The emissions provoked by heating usually show a transient emission signal that diminishes after several hours. Two to 16 hour heating cycles between $25^{\circ} \mathrm{C}$ and $80-100^{\circ} \mathrm{C}$ were carried out over several days. The emission signal is provoked repeatedly in subsequent cycles, but the integrated amounts released per heating cycle decrease in subsequent cycles. This indicates that an available limited reservoir is discharged. We note that we never observed a recharge of such a reservoir when the vial was cooled to room temperature again, which would be easily identified by an uptake of $\mathrm{CH}_{4}$, i.e., a drop of the $\mathrm{CH}_{4}$ mixing ratio below that of the incoming air. This suggests that the underlying process involves chemical reactions, since physical storage as suggested by Kirschbaum et al. (2007) should be reversible. Further work is required to investigate these heat-driven $\mathrm{CH}_{4}$ emissions, which are not well understood. Isotope labeling experiments should allow distinguishing between adsorption/desorption and chemical production mechanisms.

In sharp contrast to the heating experiments, the $\mathrm{CH}_{4}$ emissions provoked by UV light are continuous and do not drop. Having observed constant emissions in several experiments for up to one week, we attempted to determine the size of the $\mathrm{CH}_{4}$ forming reservoir and kept $1 \mathrm{~g}$ of dry grass under UV irradiation for 35 days. The high UV levels and high temperatures employed for this test resulted in an emission rate 


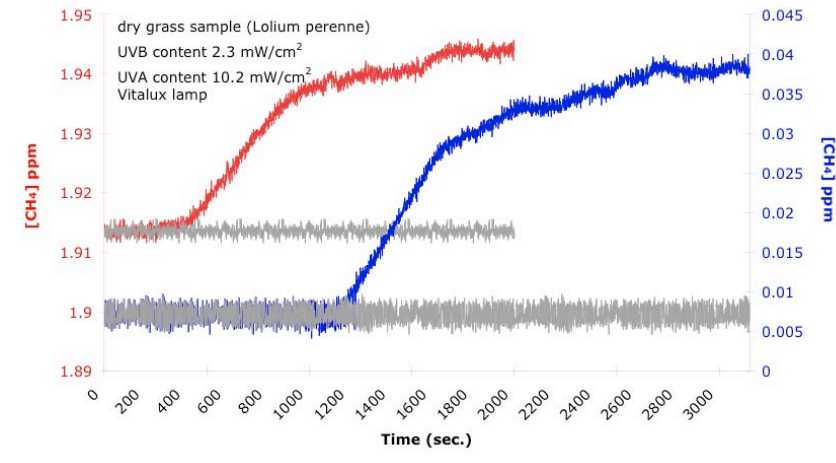

Fig. 6. $\mathrm{CH}_{4}$ emission observed from grass under UV irradiation in compressed air (right y-axis) and synthetic, methane-free air (left $\mathrm{y}$-axis). The increase in the mixing ratio is $\sim 30 \mathrm{ppb}$ for both experiments. Blank experiments without samples (grey lines) demonstrate that the emission comes from the grass sample exclusively.

of $200 \mathrm{ng} / \mathrm{g} \mathrm{dw} / \mathrm{h}$. This high emission rate was constantly monitored for 10 days, and a typical $24 \mathrm{~h}$ snapshot of raw data is shown in Fig. 5. The experiment was continued unobserved for another 20 days and monitored again for 5 days, during which the emission rate was still $200 \mathrm{ng} / \mathrm{g} \mathrm{dw} / \mathrm{h}$. This means that during those 5 weeks a total of $\sim 0.17 \mathrm{mg} \mathrm{CH}_{4}$ was formed from $1 \mathrm{~g}$ of dry grass, which by many orders of magnitude rules out any of the potential contamination sources discussed recently (Kirschbaum et al., 2007). We stress that these experiments were not carried out under typical ambient environmental conditions and we do not suggest that such amounts are produced realistically in the environment. However, the experiment shows the enormous size of the reservoir that is available. We note that the methoxyl carbons of pectin typically constitute approximately $1.4 \%$ of the carbon in plant matter, thus this reservoir is still $\sim 2$ orders of magnitude larger than the observed total emission of $\mathrm{CH}_{4}$ over 35 days.

Another test series involved several experiments in synthetic, $\mathrm{CH}_{4}$-free air Fig. 6 shows the results of two subsequent UV irradiation experiments using the same sample of dry grass (Lolium perenne), the first carried out in normal air, the second in $\mathrm{CH}_{4}$-free air after a flushing period of $24 \mathrm{~h}$ at $80^{\circ} \mathrm{C}$. In both experiments the $\mathrm{CH}_{4}$ concentration increases upon UV irradiation by $\sim 30 \mathrm{ppb}$, corresponding to an emission rate of $100 \mathrm{ng} \mathrm{CH}_{4} / \mathrm{g} \mathrm{dw} / \mathrm{h}$. Thus, the emission does not depend on the presence or absence of $\mathrm{CH}_{4}$ in the carrier air. This result is evidence against the hypothesis that adsorptiondesorption processes could be responsible for the observed emissions.

We also investigated the response time of $\mathrm{CH}_{4}$ emissions to UV irradiation Fig. 7 shows the response of a dry grass (Lolium perenne) sample to three short and strong UV pulses with the Vitalux lamp $\left(189 \mathrm{~W} / \mathrm{m}^{2} \mathrm{UVA}\right.$ and $27 \mathrm{~W} / \mathrm{m}^{2} \mathrm{UVB}$ irradiance). When the air transport time from the vial to the detector is taken into account, it is evident that emission is al-

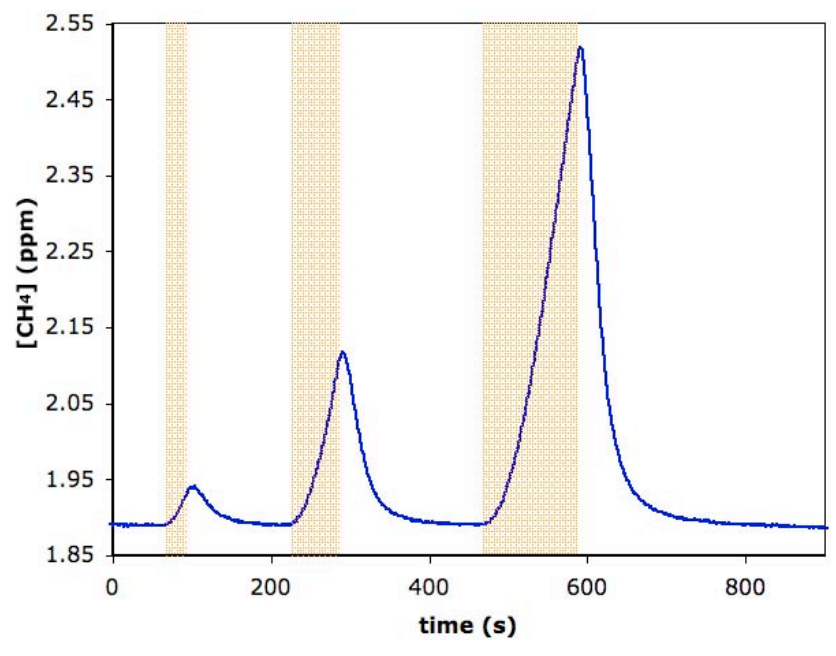

Fig. 7. Response of a grass sample (Lolium Perenne) to UV irradiation $\left(189 \mathrm{~W} / \mathrm{m}^{2} \mathrm{UVA}\right.$ and $27 \mathrm{~W} / \mathrm{m}^{2}$ UVB irradiance, Vitalux lamp). The shaded areas mark the times of illumination with the UV light source for 30, 60 and $120 \mathrm{~s}$, corrected for the flushing time of the vial and connecting lines. This flushing time was determined by adding a spike of $\mathrm{CH}_{4}$ at the inlet. It is about one minute, in agreement with the size of the vial $(100 \mathrm{ml})$ and the flow rate $(100 \mathrm{ml} / \mathrm{min})$. Taking this delay into account the response of the plant matter to light is almost instantaneous.

most instantaneous and also stops immediately after the UV source is turned off. Furthermore, the integrated emissions roughly scale with the period of irradiation. The short response time is a strong indication that a photochemical process is the source of the $\mathrm{CH}_{4}$ emission. On the other hand, the fact that the increase in concentration has not leveled off after two minutes indicates that, although the emission starts immediately after irradiation, the emission rate still increases with time of irradiation after 1-2 min. As mentioned above a free-radical mechanism has been suggested for methane formation from polysaccharides (Sharpatyi, 2007).

Dueck et al. (2007) used pure ${ }^{13} \mathrm{C}$ plants $\left(98\right.$ atom $\%{ }^{13} \mathrm{C}$ ) for their study and did not detect ${ }^{13} \mathrm{CH}_{4}$ emissions higher than $\sim 0.4 \mathrm{ng} / \mathrm{g} \mathrm{dw} / \mathrm{h}$. We obtained a fully senesced wheat (Triticum aestivum) leaf ( $\sim 100 \mathrm{mg}$; IsoLife BV, the Netherlands) used in their experiments and investigated it with our analytical setup. The emissions from this small leaf were analyzed in a $40 \mathrm{ml}$ volume static vial. Fig. 8a shows the strong buildup of ${ }^{13} \mathrm{CH}_{4}$ in these experiments. The $\delta^{13} \mathrm{C}$ value increases from the typical value of atmospheric methane of $47 \%$ o to $\sim 6000 \%$ o within one hour of UV irradiation. This translates into an emission rate of $32 \mathrm{ng}{ }^{13} \mathrm{CH}_{4} / \mathrm{g} \mathrm{dw} / \mathrm{h}$, at a UVB content three times higher than typical tropical conditions. Thus, the ${ }^{13} \mathrm{CH}_{4}$ emission rate of this ${ }^{13} \mathrm{C}$ plant is similar to the emission rate of $\mathrm{CH}_{4}$ of normal plants. 

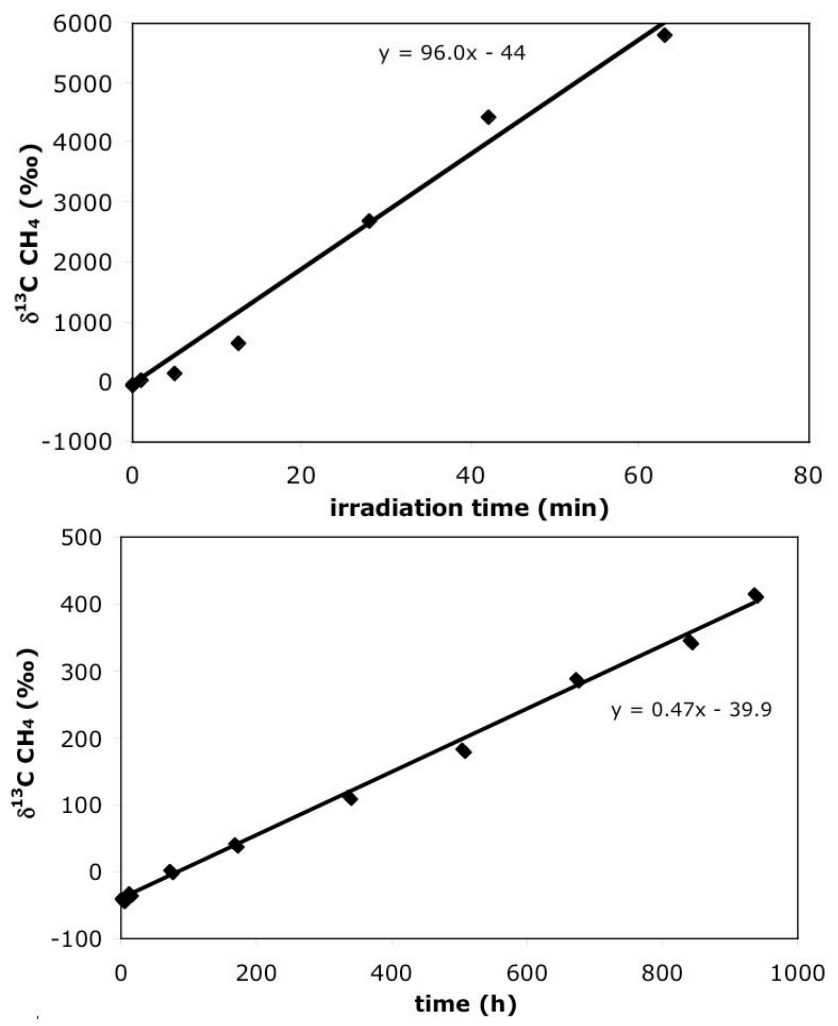

Fig. 8. ${ }^{13} \mathrm{CH}_{4}$ emission observed from a dry, senesced ${ }^{13} \mathrm{C}$ labeled wheat leaf (Triticum aestivum; 98 atom $\%{ }^{13} \mathrm{C}$ ) under UV irradiation from the VITALUX lamp ( $\left.\sim \mathrm{W} / \mathrm{m}^{2} \mathrm{UVB}\right)$ (a) and in the dark without UV (b) in two different static volumes (a, $40 \mathrm{ml}$; b, $500 \mathrm{ml}$, see text).

The huge $\delta^{13} \mathrm{C}$ signal obtained in the UV irradiation experiments illustrates the sensitivity of the isotope ratio mass spectrometry technique for those labeled experiments and we continued to determine a "dark" emission rate from this ${ }^{13} \mathrm{C}$ wheat leaf. In a $\sim 500 \mathrm{ml}$ vial stored in the laboratory without UV light and at $22^{\circ} \mathrm{C}$, we still clearly observed a steady increase of ${ }^{13} \mathrm{CH}_{4}$ over 6 weeks (Fig. 8b). The emission rate of $0.03 \mathrm{ng}{ }^{13} \mathrm{CH}_{4} / \mathrm{g} \mathrm{dw} / \mathrm{h}$ is an order of magnitude below the upper limit value given by Dueck et al. for their experiments, but can be precisely quantified with our equipment. In two additional static dark experiments at $40^{\circ} \mathrm{C}$ and $60^{\circ} \mathrm{C}$ for $16 \mathrm{~h}$ the emission rate increased to $0.6 \mathrm{ng}{ }^{13} \mathrm{CH}_{4} / \mathrm{g} \mathrm{dw} / \mathrm{h}$ at $40^{\circ} \mathrm{C}$ and $2.8 \mathrm{ng}{ }^{13} \mathrm{CH}_{4} / \mathrm{g} \mathrm{dw} / \mathrm{h}$ at $60^{\circ} \mathrm{C}$. This shows a strong temperature dependence of the emission also without UV light over the ambient temperature range. Whereas we cannot yet positively rule out that bacterial activity could be responsible for the low temperature dark emissions, the strong increase observed in the dynamic system at even higher temperatures (Fig. 3) rules out bacterial activity at least for those higher emissions. Furthermore the irradiation experiments above show that UV light increases the emissions by two orders of magnitude, and that these emissions have a non-bacterial, most likely photochemical origin.
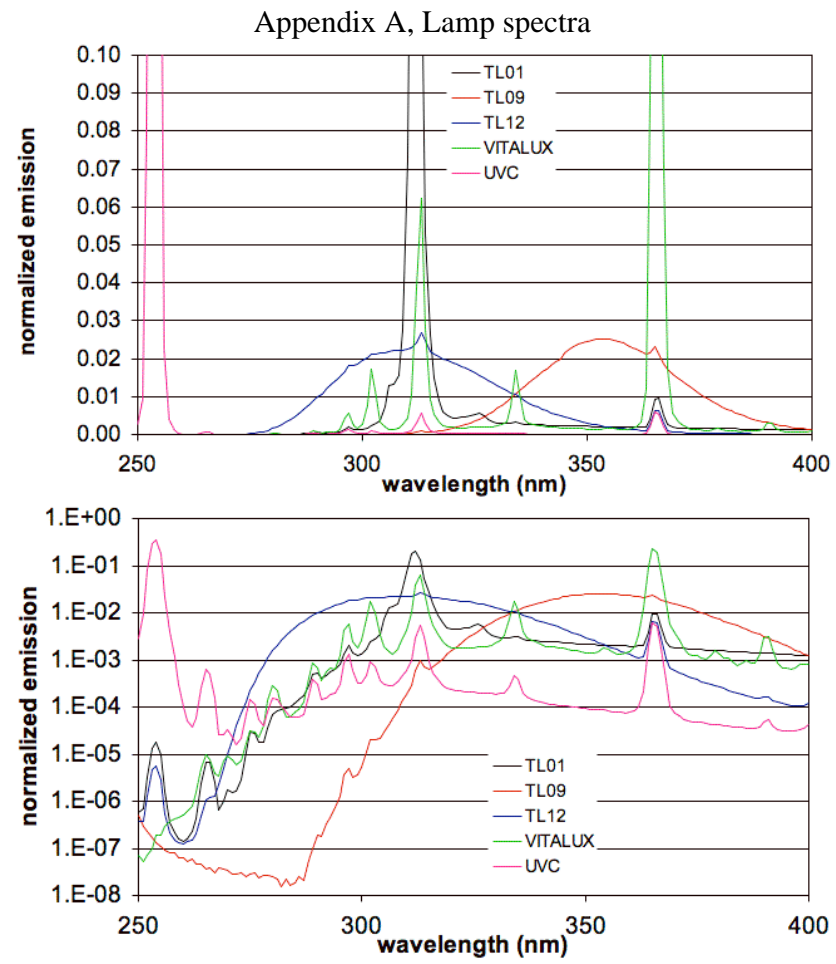

Fig. A1. UV spectra of the light sources employed in our study, obtained with a calibrated standard UV-visible spectroradiometer (model 752, Optronic Laboratories Inc, USA). Top, linear scale, bottom, logarithmic scale. The spectra are normalized to yield the same total $(250-400 \mathrm{~nm})$ UV emission.

\section{Conclusions and outlook}

Methane is produced from fresh and dry organic matter, as well as several structural plant components. UV radiation and temperature are key parameters that control $\mathrm{CH}_{4}$ formation. Our experiments suggest that UV mediated $\mathrm{CH}_{4}$ production is a ubiquitous process, that it readily occurs in the presence of oxygen and that it is not mediated by bacteria. Furthermore we can exclude physical adsorption - desorption processes or out-gassing from other reservoirs as a possible explanation for the observed methane emissions in the UV irradiation experiments. The emission rates for dry matter, on a per mass basis, are higher than those reported previously without UV light (Keppler et al., 2006). Additional experiments, e.g. isotope labeling studies as performed in (Keppler et al., 2007) are needed to further elucidate the reaction mechanisms.

We have restricted the experiments reported here to dry and detached fresh organic matter and some structural compounds in order to identify the existence of an aerobic $\mathrm{CH}_{4}$ production process without interference of potentially complicating factors from living plants (including consumption processes). As a next step, we will investigate $\mathrm{CH}_{4}$ emissions from living plants. If UV is also an important factor 
there, then it is not surprising that no emissions were found by Dueck et al. (2007), who used metal halide HPI-T lamps and glass chambers for their measurements. We note that the UV and temperature mediated $\mathrm{CH}_{4}$ emissions presented here can most likely not explain the recent results from Wang et al. (2007), who measured $\mathrm{CH}_{4}$ emissions from stems of woody species of the Mongolian Steppe region, because they carried out dark enclosure experiments in the laboratory. Keppler et al. (2006) found significantly higher emissions from living plants, which further increased when the plants were exposed to direct sunlight. We recently recorded UV transmission spectra for the static plant chambers that were used there and found that the chambers are made of two different kinds of Plexiglas; the side walls of the chamber are transparent to UVA and UVB radiation, but the top plate has a cutoff in the long wave UVA region. So solar UV penetrating through the side walls could indeed have played a role there, but the emission rates from dry and fresh leaves at natural UV levels reported above are lower than those determined by Keppler et al. (2006) from living plants. Furthermore, in that study relatively high emissions were also observed from living plants under normal laboratory conditions and this needs to be further investigated with dedicated experiments.

Acknowledgements. This work was funded by the Dutch NWO project 016.071.605. Special thanks to Ries de Visser (Isolife, Wageningen) for providing a leaf of a ${ }^{13} \mathrm{C}$ labeled wheat plant. We thank S. Houweling, M. Krol, Ü. Niinemets, C. A. M. Brenninkmeijer, M. Kirschbaum, R. de Visser and H. Poorter for useful discussion and/or comments on the manuscript. Thanks also to the people of the Utrecht Botanic Garden for providing many plant species and Cascamificio Vigano for the cotton flowers from Tadzhikistan.

Edited by: T. R. Christensen

\section{References}

Beerling, D. J., Gradiner, T., Leggett, G., McLeod, A., and Quick, W. P.: Missing methane emissions from leaves of terrestrial plants, Glob. Change Biol., 14, 1-6, doi:10.1111/j.13652486.2008.01607.x, 2008.

Bergamaschi, P., Dentener, F., Grassi, G., Leip, A., Somogyi, Z., Federici, S., Seufert, G., and Raes, F.: Methane emissions from terrestrial plants, European Commission, Luxemburg, EUR 22240 EN, ISBN 22292-22279-02007-22242, 2006.

Bergamaschi, P., Frankenberg, C., Meirink, J. F., Krol, M., Dentener, F., Wagner, T., Platt, U., Kaplan, J. O., Korner, S., Heimann, M., Dlugokencky, E. J., and Goede, A.: Satellite chartography of atmospheric methane from SCIAMACHYon board ENVISAT: 2. Evaluation based on inverse model simulations, J. Geophys. Res., 112, D02304, doi: 10.1026/2006JD007268, 2007.
Bernhard, G., Mayer, B., Seckmeyer, G., and Moise, A.: Measurements of spectral solar UV irradiance in tropical Australia, J. Geophys. Res., 102, 8719-8730, 1997.

Butenhoff, C. L. and Khalil, M. A. K.: Global methane emissions from terrestrial plants, Environ. Sci. Technol., 41, 4032-4037, 2007.

Crutzen, P., Sanhueza, E., and Brenninkmeijer, C. A. M.: Methane production from mixed tropical savanna and forest vegetation in Venezuela, Atmos. Chem. Phys. Discuss., 6, 1-5, 2006, http://www.atmos-chem-phys-discuss.net/6/1/2006/.

do Carmo, J. B., Keller, M., Dias, J. D., de Camargo, P. B., and Crill, P.: A source of methane from upland forests in the Brazilian Amazon, Geophys. Res. Lett., 33, L04809, doi:04810.01029/02005GL025436, 2006.

Dueck, T. A., de Visser, R., Poorter, H., Persijn, S., Gorissen, A., de Visser, W., Schapendonk, A., Verhagen, J., Snel, J., Harren, F. J. M., Ngai, A. K. Y., Verstappen, F., Bouwmeester, H., Voesenek, L. A. C. J., and van der Werf, A.: No evidence for substantial aerobic methane emission by terrestrial plants: a ${ }^{13} \mathrm{C}$-labelling approach New Phytologist, 175, 29-35, doi:10.1111/j.1469-8137.2007.02103.x, 2007.

Ferretti, D., Miller, J., White, J., Etheridge, D., Lassey, K., Lowe, D., Allan, B., MacFarling, C., Dreier, M., Trudinger, C., and Ommen, T. v.: Unexpected changes to the global methane budget over the past 2000 years, Science, 309, 1714-1717, 2005.

Ferretti, D., Miller, J. B., White, J. W. C., Lassey, K., Lowe, D., and Etheridge, D.: Stable isotopes provide revised global limits of aerobic methane emissions from plants, Atmos. Chem. Phys. Discuss., 6, 5867-5875, 2006,

http://www.atmos-chem-phys-discuss.net/6/5867/2006/.

Forster, P., Ramaswamy, V., Artaxo, P., Berntsen, T., Betts, R., Fahey, D. W., Haywood, J., Lean, J., Lowe, D. C., Myhre, G., Nganga, J., R. Prinn, Raga, G., Schulz, M., and Dorland, R. v.: Changes in Atmospheric Constituents and in Radiative Forcing, in: Climate Change 2007: The Physical Science Basis. Contribution of Working Group I to the Fourth Assessment Report of the Intergovernmental Panel on Climate Change edited by: Solomon, S., Qin, D., Manning, M., Chen, Z., Marquis, M., Averyt, K. B., M.Tignor, and Miller, H. L., Cambridge University Press, Cambridge, United Kingdom and New York, NY, USA, 2007.

Frankenberg, C., Meirink, J. F., van Weele, M., Platt, U., and Wagner, T.: Assessing methane emissions from global space-borne observations, Science, 308, 1010-1014, 2005.

Frankenberg, C., Meirink, J. F., Bergamaschi, P., Goede, A. P. H., Heimann, M., Korner, S., Platt, U., van Weele, M., and Wagner, T.: Satellite chartography of atmospheric methane from SCIAMACHY on board ENVISAT: Analysis of the years 2003 and 2004, J. Geophys. Res., 111, D07303, doi:07310.01029/02005JD006235, 2006.

Houweling, S., Röckmann, T., Aben, I., Keppler, F., Krol, M., Meirink, J. F., Dlugokencky, E., and Frankenberg, C.: Atmospheric constraints on global emissions of methane from plants, Geophys. Res. Lett., 33, L15821, doi:15810.11029/12006GL026162, 2006.

Houweling, S., Werf, G. v., Klein Goldewijk, K., Röckmann, T., and Aben, I.: Early anthropogenic emissions and the variation of $\mathrm{CH}_{4}$ and ${ }^{13} \mathrm{CH}_{4}$ over the last millennium, Glob. Biogeochem. Cycl., 22, GB1002, doi:10.1029/2007GB002961, 2007. 
Keppler, F., Hamilton, J. T. G., Brass, M., and Röckmann, T.: Methane emissions from terrestrial plants under aerobic conditions, Nature, 439, 187-191, doi:110.1038/nature04420, 2006.

Keppler, F., Hamilton, J. T. G., McRoberts, C. W., Vigano, I., Braß, M., and Röckmann, T.: Methoxyl groups of plant pectin as a precursor compound for atmospheric methane: evidence from deuterium labelling studies, New Phytologist, 178, 808814, doi:10.11111/j.1469.2008.02411.x, 2007.

Kirschbaum, M. U. F., Bruhn, D., Etheridge, D. M., Evans, J. R., Farquhar, G. D., Gifford, R. M., Paul, K. I., and Winters, A. J.: A comment on the quantitative significance of aerobic methane release by plants, Functional Plant Biology, 33, 521-530, 2006.

Kirschbaum, M. U. F., Niinemets, Ü., Bruhn, D., and Winters, A. J.: How important is aerobic methane release by plants?, in: Functional Plant Science and Biotechnology, Global Science Books, 138-145, 2007.

Miller, J. B., Gatti, L. V., d'Amelio, M. T. S., Crotwell, A. M., Dlugokencky, E. J., Bakwin, P., Artaxo, P., and Tans, P. P.: Airborne measurements indicate large methane emissions from the eastern Amazon basin, Geophys. Res. Lett., 34, L10809, doi:10.1029/2006GL029213, 2007.
Sanhueza, E. and Donoso, L.: Methane emission from tropical savanna Trachypogon sp. grasses, Atmos. Chem. Phys., 6, 53155319, 2006, http://www.atmos-chem-phys.net/6/5315/2006/.

Schaefer, H., Whiticar, M. J., Brook, E. J., Petrenko, V. V., Ferretti, D., and Severinghaus, J.: Ice Record of $\delta^{13} \mathrm{C}$ for Atmospheric $\mathrm{CH}_{4}$ Across the Younger Dryas - Preboreal Transition, Science, 313, 1109-1112, 2006.

Sharpatyi, V. A.: On the mechanism of methane emission by terrestrial plants, Oxidation Communications, 30, 48-50, 2007.

Sinha, V., Williams, J., Crutzen, P. J., and Lelieveld, J.: Methane emissions from boreal and tropical forest ecosystems derived from in-situ measurements, Atmos. Chem. Phys. Discuss., 7, 14011-14039, 2007, http://www.atmos-chem-phys-discuss.net/7/14011/2007/.

Wang, Z.-P., Han, X.-G., Wang, G. G., Song, Y., and Gulledge, J.: Aerobic methane emission from plants in the inner Mongolia steppe, Env. Sci. Technol., 42, 62-68, doi:10.1021/es0712241, 2007.

Zimmerman, P. R., Greenberg, J. P., Wandiga, S. O., and Crutzen, P. J.: Termites: A Potentially Large Source of Atmospheric Methane, Carbon Dioxide, and Molecular Hydrogen, Science, 218, 563-565, doi:10.1126/science.218.4572.563, 1982. 